\title{
Recurrent bronchopulmonary infections in the left lung of a 21-month-old female
}

\author{
G. Bava*, O. Sacco ${ }^{\#}$, E. Bava*, I. Borini, F. Pesce ${ }^{\star}$, P. Tomà ${ }^{+}$and G.A. Rossi ${ }^{\#}$
}

\section{CASE HISTORY}

A 21-month-old female with a history of failure to thrive after the age of 6 months and recurrent, slowly resolving bronchopulmonary infections involving the left lung and leading to respiratory distress requiring oxygen administration, was referred to the Giannina Gaslini Institute (Genova, Italy) for further evaluation.

On admission, in December 2004, the patient was in mediocre general conditions. Her height and weight were $56 \mathrm{~cm}$ and

\begin{tabular}{|c|c|c|}
\hline TABLE 1 & \multicolumn{2}{|c|}{$\begin{array}{l}\text { Results of blood and microbiological tests } \\
\text { performed on admission }\end{array}$} \\
\hline \multicolumn{2}{|c|}{ Haemoglobin } & $114 \mathrm{~g} \cdot \mathrm{L}^{-1}$ \\
\hline \multicolumn{2}{|c|}{ White blood cell count } & $11.7 \times 10^{9} \mathrm{cells} \cdot \mathrm{L}^{-1}$ \\
\hline \multicolumn{2}{|c|}{ Platelet count } & $468.0 \times 10^{9}$ cells $\cdot \mathrm{L}^{-1}$ \\
\hline \multicolumn{2}{|c|}{ Erythrocyte sedimentation rate first hour } & $15 \mathrm{~mm}$ \\
\hline \multicolumn{2}{|c|}{ C-reactive protein } & $4.1 \mathrm{~g} \cdot \mathrm{L}^{-1}$ \\
\hline \multicolumn{2}{|c|}{ Serum protein } & Normal \\
\hline \multicolumn{2}{|c|}{ Immunoglobulin electrophoresis } & Normal \\
\hline \multicolumn{2}{|c|}{$\begin{array}{l}\text { Antinuclear antibodies, antineutrophil } \\
\text { cytoplasmic antibodies }\end{array}$} & Negative \\
\hline \multicolumn{2}{|c|}{ Rheumatoid factor } & $<80 \mathrm{kIU} \cdot \mathrm{L}^{-1}$ \\
\hline \multicolumn{2}{|c|}{ Cold agglutinin } & Negative \\
\hline \multicolumn{2}{|c|}{ Antistreptolysin-O titre } & $230 \mathrm{IU} \cdot \mathrm{L}^{-1}$ \\
\hline \multicolumn{2}{|c|}{ Phagocytic oxidative metabolism } & Normal \\
\hline \multicolumn{2}{|c|}{$\begin{array}{l}\text { Transcutaneous blood arterial oxygen } \\
\text { tension determination in room }\end{array}$} & $11.4 \mathrm{kPa}$ \\
\hline \multicolumn{2}{|c|}{$\begin{array}{l}\text { Transcutaneous blood arterial carbon } \\
\text { dioxide tension determination in room }\end{array}$} & $5.1 \mathrm{kPa}$ \\
\hline \multicolumn{2}{|c|}{$\begin{array}{l}\text { Stains and culture of blood, pharyngeal } \\
\text { aspirate, urine }\end{array}$} & Negative \\
\hline \multicolumn{2}{|c|}{ Tuberculin skin test } & Negative \\
\hline
\end{tabular}

$10.0 \mathrm{~kg}$ (both $25^{\text {th }}$ percentile), respectively. Her respiratory rate was 33 breaths $\cdot \mathrm{min}^{-1}$. Physical examination demonstrated decreased percussion and auscultatory sounds over the left hemithorax. Screening on immunological disorders revealed that B- and T-cell functions were normal. Sweat test and cystic fibrosis transmembrane regulator gene mutations were negative. Results of the blood and microbiological tests performed on admission are shown in table 1.

A chest radiograph was then carried out as shown in figure 1. Spiral computed tomography (CT) was then performed (fig. 2), followed by echocardiography (fig. 3). The patient underwent cardiac catheterisation and angiography (fig. 4).

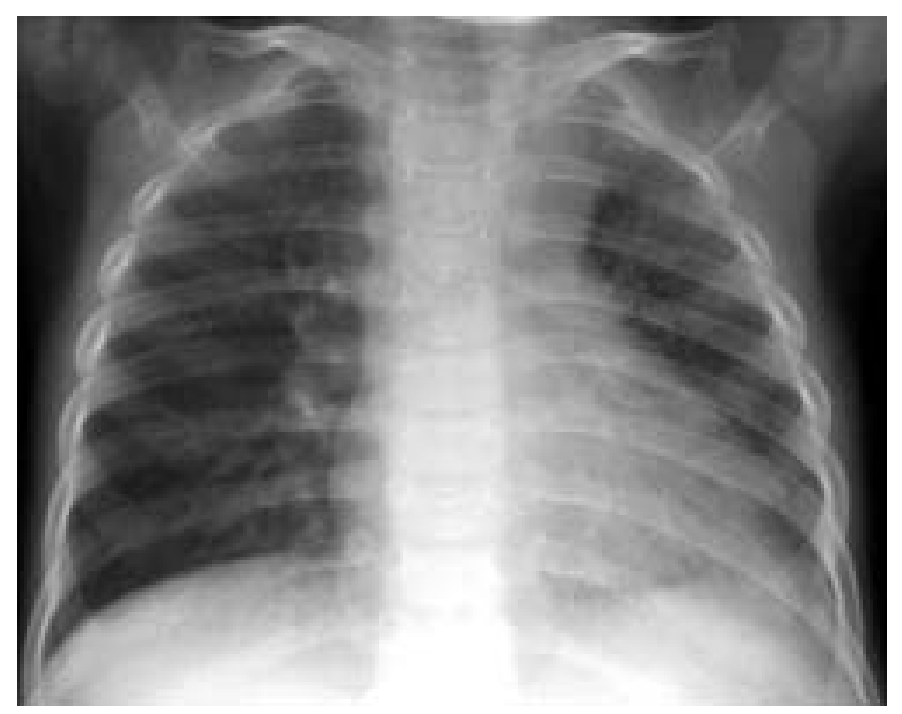

FIGURE 1. Chest radiograph on presentation.

Depts of ${ }^{*}$ Cardiovascular Surgery, ${ }^{\#}$ Pulmonology, and ${ }^{+}$Radiology, G.Gaslini Institute, Genoa, and "Dept of Paediatrics, SS Antonio and Biagio and Cesare Arrigo Hospital, Alessandria, Italy. CORRESPONDENCE: G.A. Rossi, Pulmonary and Allergy Units, Giannina Gaslini Institute, Largo G. Gaslini, 5, 16147 Genova, Italy. Fax: 39 010383953. E-mail: giovannirossi@ospedale-gaslini.ge.it SUPPORT STATEMENT: This study was supported by Ricerca Corrente, Ministero della Salute, Rome, Italy. 

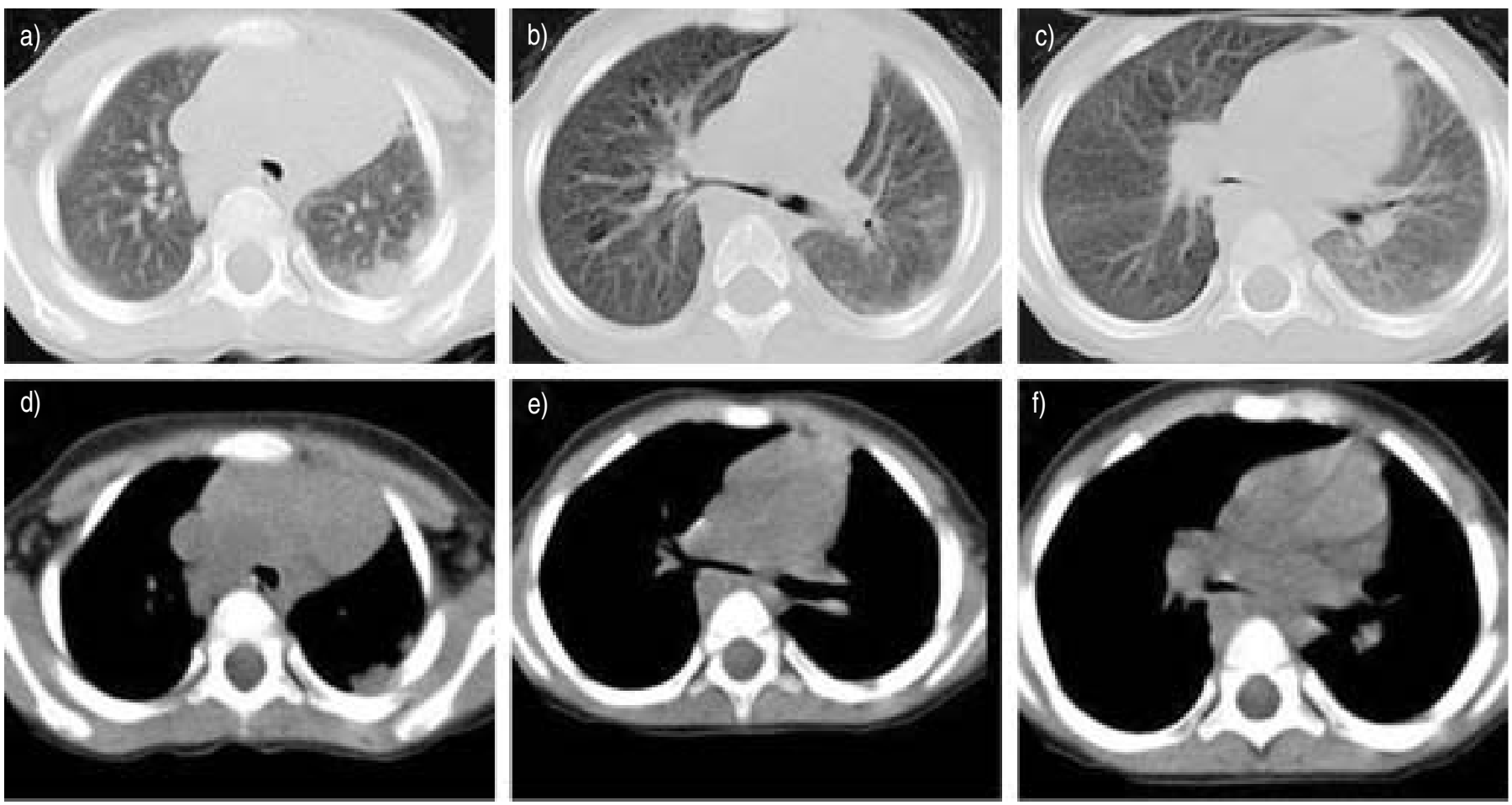

FIGURE 2. Spiral computed tomography images of the chest at different levels. a, b and c) lung windows. $d$, e and f) soft tissue windows.
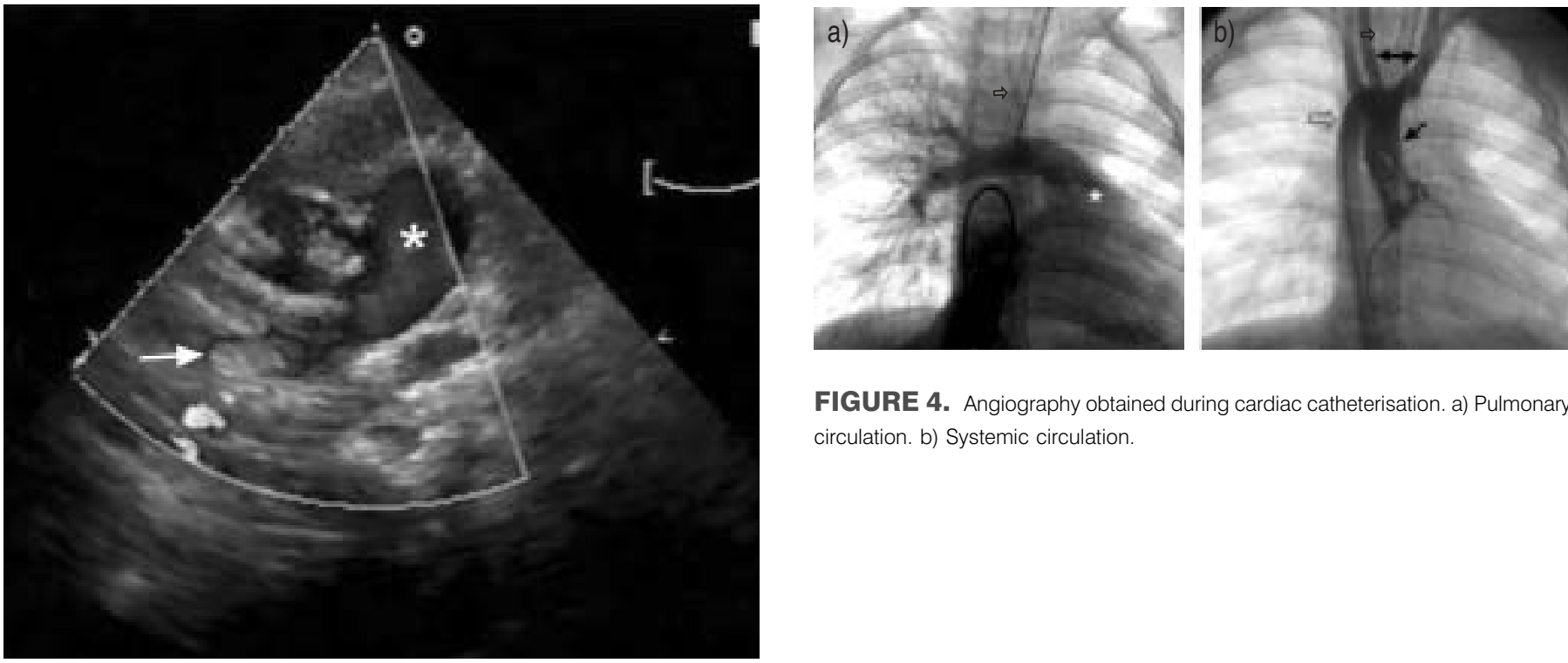

FIGURE 4. Angiography obtained during cardiac catheterisation. a) Pulmonary circulation. b) Systemic circulation.

FIGURE 3. Echocardiograph obtained on admission.

BEFORE TURNING THE PAGE INTERPRET THE RADIOGRAPH, COMPUTED TOMOGRAPHY SCANS, ECHOCARDIOGRAPHY AND ANGIOGRAPHY, SUGGEST A DIAGNOSIS AND A POSSIBLE CAUSE. 


\section{INTERPRETATION}

\section{Chest radiography}

The chest radiograph showed asymmetry of the two lung fields, with widening of the left area of the mediastinum and a leftward mediastinal shift and possible hypoplasia of the left lung (fig. 1).

\section{Spiral computed tomography}

Besides defining the asymmetry of the two lungs and the mediastinal shift to the left more clearly, spiral CT demonstrated: 1) narrowing of the tracheal lumen, possibly due to extrinsic compression (fig. $2 \mathrm{a}$ and $2 \mathrm{~d}$ ); 2) reduced lumen of the right main-stem bronchus (fig. $2 b$ and $2 \mathrm{e}$ ); 3) hazy left lung with a small hilar shadow (fig. $2 \mathrm{~b}$ and $2 \mathrm{c}$ ); and 4 ) enlargement of the right pulmonary artery with absence of the left pulmonary artery (fig. 2c and 2f).

\section{Echocardiography}

Echocardiography showed a normal arterial pulmonary trunk (fig. 3, indicated by the asterisk) with an enlarged right pulmonary artery (downward-pointing open arrow). The left pulmonary artery could not be visualised.

\section{Angiography}

Angiography carried out during cardiac catheterisation showed agenesis of the left pulmonary artery (fig. 4a, indicated by the asterisk) and the presence of right aortic arch (fig. $4 \mathrm{~b}$, indicated by the downward-pointing open arrow), with mirror image branching (double-headed arrow) and right descending aorta (downward-pointing solid arrow). On both angiographical images, the endotracheal tube is shifted to the left (rightpointing open arrow), which is another indirect sign for possible left lung hypoplasia.

\section{Diagnosis: Agenesis of the left pulmonary artery and hypoplasia of the left lung, combined with right aortic arch and right descending aorta.}

\section{CLINICAL COURSE}

A median sternotomy was performed, through which the right aortic arch with mirror image branching was identified and the absence of the left pulmonary artery confirmed. A right ligamentum arteriosum, running between the right descending aorta and the enlarged right pulmonary artery, was found and divided. The right pulmonary artery was isolated and then suspended to the ascending aorta, increasing the space for the right bronchus. After surgery the patient was extubated in the operating room. Comparisons between the intra-operative fibreoptic bronchoscopies performed before and after surgery demonstrated that the surgical procedure resulted in complete decompression of the trachea, but persistency of mild ovalisation of the right main-stem bronchus.

At a follow-up visit, performed 4 months after surgery, the patient was in good general condition, demonstrated a normal somatic growth, and no more lower respiratory tract infectious episodes were reported by the parents.

\section{DISCUSSION}

Lower respiratory infections are a relatively frequent cause of illness and hospitalisation in children, with a reported incidence of: $\sim 4 \%$ per $\mathrm{yr}$ in children $<5 \mathrm{yrs}$ old; $2 \%$ per $\mathrm{yr}$ in children 5-9 yrs old; and 1\% per yr in older children and adolescents $[1,2]$. A small proportion of these children develop recurrent or persistent lower respiratory symptoms $[2,3]$. In considering the aetiology of recurrent or chronic pneumonias, it is helpful to classify the process with respect to anatomical distribution in the lungs. Diffuse disease or disseminated pulmonary infiltrates is consistent with the possible presence of metabolic, immunological or neurological abnormalities; whereas recurrent involvement in a single lung, lobe or segment may suggest malformations of the airway or the parenchymal structures, or segmental obstruction of the airways with resulting atelectasis or pulmonary hyperinflation [1-4].

Congenital anomalies of the heart and great vessels may lead to localised recurrent pulmonary infections through three different mechanisms as follows. 1) Reduced blood supply and defective ventilation, as seen in lung parenchymal hypoplasia, due to pulmonary artery defects [5]. 2) Altered venous pulmonary circulation as observed in congenital pulmonary vein stenosis, a disease characterised by obliteration of the lumen of the primary pulmonary veins at or near the venoatrial junction [6]. 3) Extrinsic compression of the large airways by the great vessels [7]. Congenital anomalies of the great intrathoracic vessels leading to extrinsic airway narrowing classically include a double aortic arch, innominate artery compression, pulmonary artery slings, and vascular rings consisting of the right aortic arch, anomalous origin of the left subclavian artery and ligamentum arteriosus [7]. Airway narrowing may be caused by severe direct compression or by progressive airway weakening with localised bronchomalacia and may be associated with other respiratory symptoms, in addition to recurrent infectious complications, such as wheeze, stridor and chronic cough and dyspnoea [1-3, 8, 9]. Dysphagia may be present when congenital anomalies of the great vessels also lead to extrinsic compression of the oesophagus, such as in the double aortic arch [7]. Haemoptysis may occur due to increased blood flow and pulmonary hypertension in the opposite lung due to unilateral absence of a pulmonary artery with hypoplasia of the ipsilateral lung [10], such as in the case reported here.

The congenital anomaly reported in this case, i.e. right aortic arch, right descending aorta, agenesis of the left pulmonary artery and right lygamentum arteriosum, has been previously described only once before in literature, in a 5-month-old female presenting with a history of acute coughing, wheezing, and tachypnoea with fever and progressive respiratory failure [11]. In that patient, fibreoptic bronchoscopy, a high-resolution computed tomography scan and cardiac catheterisation revealed a right aortic arch, large right pulmonary artery and absence of the left pulmonary artery, with compression of the right main-stem bronchus between the pulmonary artery anteriorly and the right-sided descending posterior thoracic aorta [11].

In the present patient, narrowing of the distal portion of the trachea and of the right main-stem bronchus was due to compression, anteriorly by the ligamentum arteriosum and the enlarged right pulmonary artery, and posteriorly by the descending aorta. Despite the complexity of the intrathoracic vessel malformation, the only respiratory symptom observed 
in the patient was the recurrence of localised pulmonary infections in the left hypoplastic lung. The airway narrowing at the tracheal and right main-stem bronchus level was not severe enough to produce detectable signs at physical examination, but could probably contribute to the respiratory distress observed during the infectious episodes. After surgery the tracheal obstruction was almost completely relieved by surgical resection of the ligamentum arteriosum and pexis of the enlarged right pulmonary artery to the ascending aorta. The right bronchial stenosis was only partially modified, probably because of the persistency of the enlarged pulmonary artery receiving the whole cardiac output.

Recurrent or persistent respiratory symptoms, often associated with focal signs and findings, may be caused by unusual forms of vascular rings, only partially predictable on the basis of clinical presentations, physical examination and plain chest radiographs [12]. A child who has recurrent or persistent focal symptoms and/or abnormalities on chest radiographs may need early consideration of computed tomography of the intrathoracic structures, fibreoptic bronchoscopy, magnetic resonance or angiography $[3,12]$. When the diagnosis is made, the results of the multiple diagnostic investigations performed may allow accurate pre-operative planning and evaluation of the structural results obtained by treatment [13].

\section{REFERENCES}

1 Craven EM. Persistent/recurrent pneumonia in infants and children. Del Med J 1991; 63: 537-546.

2 Vaughan D, Katkin JP. Chronic and recurrent pneumonias in children. Semin Respir Infect 2002; 17: 72-84.
3 Panitch HB. Evaluation of recurrent pneumonia. Pediatr Infect Dis J 2005; 24: 265-266.

4 Wald ER. Recurrent pneumonia in children. Adv Pediatr Infect Dis 1990; 5: 183-203.

5 Hislop AA. Airway and blood vessel interaction during lung development. J Anat 2002; 201: 325-334.

6 Sacco O, Fregonese B, Fregonese L, Gambini C, Pongiglione G, Rossi GA. Unilateral interstitial fibrosis and pulmonary vein stenosis in a 4 yr old girl: successful treatment with endovascular stent implantation during cardiac catheterization. Ped Pulmonol 2002; 34: 324-328.

7 Anand R, Dooley KJ, Williams WH, Vincent RN. Followup of surgical correction of vascular anomalies causing tracheobronchial compression. Pediatr Cardiol 1994; 15: 58-61.

8 Mobeireek AF. A preoperative consultation for a patient with chronic cough and wheeze. Eur Respir 1998; 11: 785-786.

9 Dahlen IB, Hillerdal GN, Wegenius GA, Henze AC. Breathlessness in a teenager. Eur Respir J 1993; 6: 145-147.

10 Kuo PH, Wu HD, Lee LN. A patient with haemoptysis and a smaller right lung. Eur Respir J 1996; 9: 847-849.

11 Dodge-Khatami A, Backer CL, Dunham ME, Mavroudis C. Right aortic arch, right ligamentum, absent left pulmonary artery: a rare vascular ring. Ann Thorac Surg 1999; 67: 1472-1474.

12 Robotin MC, Bruniaux J, Serraf A, et al. Unusual form of tracheobronchial compression in infants with congenital heart disease. J Thorac Cardiovas Surg 1996; 112: 415-423.

13 Alboliras ET, Backer CL, Holinger LD. Pulmonary artery sling: diagnostic and management strategy. Pediatrics 1996; 98: 530 . 